\title{
Structural and functional multiplicity of the kisspeptin/GPR54 system in goldfish (Carassius auratus)
}

\author{
Shuisheng Li ${ }^{1, *}$, Yong Zhang ${ }^{1, *}$, Yun Liu ${ }^{1}$, Xigui Huang ${ }^{2}$, Weiren Huang ${ }^{1}$, Danqi Lu, \\ Pei Zhu ${ }^{1}$, Yu Shi ${ }^{1}$, Christopher H K Cheng ${ }^{2}$, Xiaochun Liu ${ }^{1}$ and Haoran Lin ${ }^{1,3}$ \\ ${ }^{1}$ State Key Laboratory of Biocontrol, Institute of Aquatic Economic Animals, and the Guangdong Province Key Laboratory for Aquatic Economic Animals, \\ Sun Yat-Sen University, Guangzhou 510275, People's Republic of China \\ ${ }^{2}$ Department of Biochemistry, The Chinese University of Hong Kong, School of Biomedical Sciences, Shatin, N.T., Hong Kong, People's Republic of China \\ ${ }^{3}$ College of Ocean, Hainan University, Haikou 570228, People's Republic of China \\ (Correspondence should be addressed to X Liu; Email: Isslxc@mail.sysu.edu.cn) \\ *(S Li and Y Zhang contributed equally to this work)
}

\begin{abstract}
To ascertain the neuroendocrine function of the kisspeptin/ GPR 54 system in non-mammalian species, full-length cDNAs encoding for Kiss 1 and Kiss 2 as well as their putative cognate receptors GPR 54a and GPR54b, were isolated from goldfish (Carassius auratus). The deduced protein sequences between Kiss1 and Kiss2 in goldfish share very low similarity, but their putative mature peptides (kisspeptin-10) are relatively conserved. RT-PCR analysis demonstrated that the goldfish kiss 1 gene ( gfkiss 1) is highly expressed in the optic tectum-thalamus, intestine, kidney, and testis, while the goldfish kiss 2 gene (gfkiss2) is mainly detected in the hypothalamus, telencephalon, optic tectum thalamus, adipose tissue, kidney, heart, and gonads. The two receptor genes (gfgpr $54 a$ and gfgpr 54b) are highly expressed in the brain regions including telencephalon, optic tectum thalamus, and hypothalamus. Both mature
\end{abstract}

goldfish kisspeptin-10 peptides (gfKiss1-10 and gfKiss2-10) are biologically active as they could functionally interact with the two goldfish receptors expressed in cultured eukaryotic cells to trigger the downstream signaling pathways with different potencies. The actions of gfKiss $1-10$ and gfKiss $2-10$ on $\mathrm{LH}$ secretion were further investigated in vitro and in vivo. Intraperitoneal administration of gfKiss $1-10$ to sexually mature female goldfish could increase the serum LH levels. However, this peptide does not significantly influence LH release from goldfish pituitary cells in primary culture, indicating that the peptide does not exert its actions at the pituitary level. On the other hand, gfKiss $2-10$ appears to be a much less potent peptide as it exhibits no significant in vivo bioactivity and is also inactive on the primary pituitary cells. Journal of Endocrinology (2009) 201, 407-418

\section{Introduction}

Kisspeptin, the product of the kiss 1 gene, was originally identified as a metastasis suppressor in breast cancer and melanoma cell lines (Lee et al. 1996, Lee \& Welch 1997). In 2003, two independent groups reported that loss-of-function mutations in the G protein-coupled receptor 54 (gpr54), the kisspeptin receptor, led to hypogonadotrophic hypogonadism (De Roux et al. 2003, Seminara et al. 2003). In addition, knockout of either the kiss 1 or gpr54 gene severely impairs the hypothalamic-pituitary-gonadal axis in mice, suggesting that the kisspeptin/GPR54 system plays an important role in mammalian reproduction (Funes et al. 2003, Seminara et al. 2003, d' Anglemont de Tassigny et al. 2007, Lapatto et al. 2007).

In mammals, several mature peptides including kisspeptin-54, $-14,-13$ and -10 are generated by proteolytic cleavage of the kisspeptin precursor with equal biopotency to activate GPR54 (Kotani et al. 2001, Muir et al. 2001, Ohtaki et al. 2001). Kisspeptin neurons are mainly located in the arcuate nucleus and anteroventral periventricular nucleus (Matsui et al. 2004, Irwig et al. 2005). These neurons send projections into the preoptic area where gpr 54 is expressed in the GnRH neurons (Matsui et al. 2004, Irwig et al. 2005). Kisspeptin activates the GnRH neurons to stimulate $\mathrm{GnRH}$ release (Gottsch et al. 2004, Messager et al. 2005, Shahab et al. 2005). At very low dose, central administration of kisspeptin markedly elicits LH release in mouse (Gottsch et al. 2004, Messager et al. 2005), rat (Navarro et al. 2004, Irwig et al. 2005), sheep (Messager et al. 2005) and monkey (Shahab et al. 2005, Plant et al. 2006). The LH-releasing action of kisspeptin could be eliminated by pretreatment with $\mathrm{GnRH}$ antagonists (Gottsch et al. 2004, Irwig et al. 2005). At the pituitary level, however, the effects of kisspeptin on LH release are controversial. Some studies indicated that kisspeptin could stimulate LH release from the pituitary (Gutierrez-Pascual et al. 2007, Suzuki et al. 2008), while 
others failed to demonstrate similar effects (Matsui et al. 2004, Thompson et al. 2004, Smith et al. 2008). The discovery of the kisspeptin/GPR54 system has greatly enhanced our understanding of the neuroendocrine regulation of reproduction in various aspects including the molecular timing of puberty onset, the negative and positive feedback control of gonadotropin secretion by sex steroids, the mechanism of sexual dimorphism, the regulation of seasonal reproduction, and the integration of energy homeostasis and reproduction (Kauffman et al. 2007, Popa et al. 2008).

In lower vertebrates, however, the role and significance of the kisspeptin/GPR54 system in the neuroendocrine regulation of reproduction remains to be established. Recently, two kiss 1 genes, namely kiss 1 and kiss2, were identified in zebrafish and medaka (Kitahashi et al. 2008) as well as in sea bass (Felip et al. 2008). Kiss2 peptide administration could stimulate LH $\beta$-subunit and FSH $\beta$-subunit mRNA expression in the pituitary of sexually mature female zebrafish (Kitahashi et al. 2008). In sea bass, the two kisspeptins were able to induce LH and FSH secretion (Felip et al. 2008). In addition, two types of gpr $54 \mathrm{~s}$ have been identified in zebrafish (Biran et al. 2008). However, a systematic study in a single fish species demonstrating the interplay between the two ligands and the two putative cognate receptors is lacking. Moreover, given that fish consist of evolutionarily divergent species, further studies in different species are highly warranted to reveal other important aspects of kisspeptins on the regulation of fish reproduction. In this study, we have therefore employed goldfish, a recognized model organism for studying the neuroendocrine control of reproduction in lower vertebrates (Popesku et al. 2008), to study the role of the kisspeptin/GPR54 system on the neuroendocrine regulation of $\mathrm{LH}$ release in fish.

\section{Materials and Methods}

\section{Animals and chemicals}

Goldfish were obtained from a local fish farm in Guangzhou, China. Tissue samples were collected immediately from decapitated goldfish and snap frozen in liquid nitrogen. All animal experiments were conducted in accordance with the guidelines and approval of the respective Animal Research and Ethics Committees of Sun Yat-Sen University.

Peptides corresponding to goldfish kisspeptins (gfKiss1-10 and gfKiss2-10) and [D-Ala6, Pro9NEt]-LH-releasing hormone (LHRHa) were synthesized by Ningbo Fish Hormone Factory, Zhejiang Province, China. The purity was $>95 \%$ as determined by analytical HPLC.

\section{Molecular cloning of goldfish kiss $1 \mathrm{~s}$ and GPR $54 \mathrm{~s}$ cDNAs}

Total RNA from goldfish brain was prepared using Trizol reagent (Invitrogen). One microgram of isolated RNA was used to synthesize the first-strand cDNA using the ReverTra
Ace- $\alpha$ first-strand cDNA Synthesis Kit (Toyobo, Osaka, Japan). Partial cDNA fragments were first obtained by PCR using degenerate primers or gene-specific primers designed according to the predicted sequences. Full-length cDNA sequences were obtained by the RACE using the GeneRacer Kit (Invitrogen). All primers used in the present study are listed in Table 1.

For all PCR reactions in this study, amplifications were performed with an initial denaturation at $94^{\circ} \mathrm{C}$ for $3 \mathrm{~min}$, followed by 35 cycles of $94{ }^{\circ} \mathrm{C}$ for $15 \mathrm{~s}, 52-58{ }^{\circ} \mathrm{C}$ for $15 \mathrm{~s}$ and $72{ }^{\circ} \mathrm{C}$ for $1-1.5 \mathrm{~min}$. The reaction was ended by a further extension of $10 \mathrm{~min}$ at $72{ }^{\circ} \mathrm{C}$. The amplification products were purified using the E.Z.N.A. Gel Extraction Kit (Omega BioTek, GA, USA) and ligated into the $\mathrm{pTZ57R/T}$ vector (Fermentas, MD, USA). Three different individual positive clones were sequenced to confirm the sequence information on an ABI 3700 sequencer (Applied Biosystems).

\section{Sequence analysis}

The signal peptide and the neuropeptide prohormone cleavage sites were predicted using the SignalP3.0 (Bendtsen et al. 2004) and Neuropred software (Southey et al. 2006) respectively. Multiple sequence alignments were performed using ClustalW (Thompson et al. 1994), and the phylogenetic trees were constructed by MEGA 3.1 using the neighborjoining method (Kumar et al. 2004).

RT-PCR analysis for tissue expression of kiss $1 \mathrm{~s}$ and gpr54s in goldfish

To detect the tissue expression profiles of kiss $1 \mathrm{~s}$ and gpr $54 \mathrm{~s}$ in goldfish, total RNA from different tissues of goldfish was isolated including telencephalon, optic tectum thalamus, hypothalamus, cerebellum, medulla, pituitary, liver, adipose tissue, intestine, gill, heart, kidney, testis, and ovary. One microgram of total RNA from each tissue was digested with DNase I and reverse-transcribed (RT) into cDNA using the ReverTra Ace-first-strand cDNA Synthesis Kit (Toyobo). Mock RT reactions without the reverse transcriptase were used as negative controls.

\section{Cell culture, transfection, and functional assays}

The open reading frame (ORF) of the gfGPR54a and gfGPR 54b cDNAs were subcloned into the pcDNA3.1 expression vector (Invitrogen). The COS-7 cell line was obtained from ATCC (Manassas, VA, USA). Cells were maintained at $37^{\circ} \mathrm{C}$ in DMEM containing $10 \%$ fetal bovine serum (FBS). All media were supplemented with antibiotics (10 U/ml penicillin and $100 \mu \mathrm{g} / \mathrm{ml}$ streptomycin).

Twenty hours before transfection, $1.5 \times 10^{5}$ cells/well were seeded into 24-well tissue-culture plates. Five hundred nanograms of the pSRE-Luc or pCRE-luc reporter plasmid 
Table 1 The primers used in the present study

Sequences (from $5^{\prime}$ to $3^{\prime}$ )

\section{Primer}

Primers for gfGPR54b partial cDNA

GPR54bF1 ACCGATATACTTTTCCTGGT

Primers for gfGPR54b, gfKiss1 and gfKiss2 $3^{\prime}$ end

$\begin{array}{ll}\text { GPR54bF2 (first) } & \text { TATGTTCTTTGCTGCTTTCGG } \\ \text { Kiss1F1 (first) } & \text { CTACAATCTCAACTCCTTCG }\end{array}$

Kiss2F1 (first) GCACGCGRAAYTTC AAC

Primers for gfGPR54b, gfKiss 1 and gfKiss2 $5^{\prime}$ end

GPR54bR2 (first) TCTGGTCCGCACTGCTTCAA

Kiss1R1 (first) TCCTTTTATTCAGATTGTTTG

Kiss2R1 (first) ATTACGGACTGAAACAAGCG

Primers for ORF of gfGPR54a, gfGPR54b, gfKiss1 and gfKiss2

GPR54aF1 GAAAAACTGCCTCAGTGAC

GPR54bF4 CTGAAAGAGGTTATTGCTAG

Kiss1F3 AATGAAGCTACTTACCATC

Kiss2F3 CAGCTGTGCTCCATAAGCT

Primers for tissue distribution

GPR54aF2

GPR54bF5

Kiss1F4

Kiss2F4

$18 \mathrm{~S} \mathrm{~F}$
CCGCCACTAACTTTTACATTG TATGTTCTTTGCTGCTTTCGG ACACAAAAAGGAAGCAGAATG GCAGTTTGACGAGCCCAGTTC AGCAACTTTAGTATACGCTATTGGAG
Primer

GPR54bR1

GPR54bF3 (neste)
Kiss1F2 (neste)
Kiss2F2 (neste)
GPR54bR3 (neste)
Kiss1R2 (neste)
Kiss2R2 (neste)
GPR54aR1
GPR54bR4
Kiss1R1
Kiss2R1
GPR54aR1
GPR54bR5
Kiss1R3
Kiss2R3
18S R

Sequences (from $5^{\prime}$ to $3^{\prime}$ )

GTGTAGCTGCGGCTCACGTCT

ATCAGCACACAGAGTCTTCGT ACTCCTTCGGCCTCCGCTAT TTCAACTACAARCCGTTTGG

AACAGCAGCACCATTACAACC CTAAAGTCTGTGAACTATTGC TTACCCACAGTTTTCCATTCT

CGACTAGACAGTTGGCATG AGCCTTTCCAAAACGCCTAG TCCTTTTATTCAGATTGTTTG ATTACGGACTGAAACAAGCG

TTCAGAGGATACACAGTCACA TCTGGTCCGCACTGCTTCAA CCTCAACGAACAATACACAAG AAATCATCATTGGCAGCAGGT CCTGAGAAACGGCTACCACATCC

Mixed bases: $\mathrm{Y}=\mathrm{G}+\mathrm{A} ; \mathrm{R}=\mathrm{C}+\mathrm{T}$.

(Stratagene, La Jolla, CA, USA), 100 ng pcDNA-gfGPR54a or pcDNA-gfGPR54b, and 50 ng pRL-CMV (for normalization of transfection efficiency) containing the Renilla luciferase reporter gene were co-transfected into the cells in $250 \mu \mathrm{l}$ serum-free medium using Lipofectamine reagent (Invitrogen). Six hours after transfection, cells were incubated with vehicle or various (from $10^{-10}$ to $10^{-6} \mathrm{M}$ ) concentrations of gfKiss1-10 or gfKiss $2-10$ for a further $20 \mathrm{~h}$. Luminescence was measured on a Lumat LB 9501 luminometer (EG \& G, Berthold, Germany) and the activities of both luciferases were measured sequentially on the same sample. Transfection experiments were performed in triplicate in three independent experiments. A paralleled control transfection experiment was performed with only pcDNA3.1, cAMP response element (CRE) or serum response element (SRE) promoter and an internal control pRL/CMV.

In vitro actions of goldfish kisspeptins on LH secretion from goldfish pituitary cells in primary culture

Sexually mature female goldfish were anesthetized in $0.05 \%$ tricaine methanesulfonate before decapitation. Pituitary was removed and washed three times with Hank's balanced salt solution without $\mathrm{Ca}^{2+}$ and $\mathrm{Mg}^{2+}$ (HBSS). Pituitaries were diced into small pieces of $1 \mathrm{~mm}^{3}$ dimension, and digested with $1 \mathrm{mg} / \mathrm{ml}$ trypsin (Invitrogen) at $25{ }^{\circ} \mathrm{C}$ for $60 \mathrm{~min}$. The protease digestion was terminated by $1 \mathrm{mg} / \mathrm{ml}$ trypsin inhibitor (Sigma-Aldrich). After further digestion with $25 \mu \mathrm{g} / \mathrm{ml}$ DNase I (Invitrogen), the pituitary cells were then washed with calcium-free HBSS solution containing
$1 \mathrm{mM}$ EGTA and filtered through a $100 \mu \mathrm{m}$ nylon membrane. Pituitary cells were harvested by centrifugation (200 $\mathrm{g}$ for $15 \mathrm{~min}$ ) and were resuspended in Hanks salt medium 199 (M199). The viability of the cells, tested by the trypan-blue method, was $>90 \%$. Cells were seeded at a density of $2 \cdot 5 \times 10^{5}$ cells/well on poly-L-lysine-coated 24-well dishes in $1 \mathrm{ml}$ M199 containing $100 \mathrm{U} / \mathrm{ml}$ penicillin, $100 \mu \mathrm{g} / \mathrm{ml}$ streptomycin, and 5\% FBS. After preincubation at $25{ }^{\circ} \mathrm{C}$ for $24 \mathrm{~h}$, the medium was aspirated away and replaced with a fresh medium containing the test peptides (goldfish kisspeptins and LHRHa). The culture media were harvested after incubation for 0.5 and $3 \mathrm{~h}$, and were stored at $-80^{\circ} \mathrm{C}$ until measurement of LH by RIA.

In vivo effects of goldfish kisspeptins on LH secretion in goldfish

Sexually mature female goldfish, 120-140 g body weight, were kept in indoor tanks supplied with constant water flow. The fish were acclimatized to the environment for 2 weeks and feed on commercially available fish foods without any supplemented hormones. The test peptides were dissolved in a vehicle of $0 \cdot 7 \% \mathrm{NaCl}$. Fish were anesthetized with $0 \cdot 05 \%$ tricaine methanesulfonate and intraperitoneally injected with various doses of the test peptides twice with a $3 \mathrm{~h}$ internal. The LHRHa injected group was used as the positive control. Negative control fish were administrated with $0 \cdot 7 \% \mathrm{NaCl}$ only. Blood samples were collected from the caudal vessels at 2 and $6 \mathrm{~h}$ after the second injection. Serum samples were separated by centrifugation and stored at $-80^{\circ} \mathrm{C}$ until measurement of LH by RIA. 


\section{Hormone measurements}

LH levels in the serum samples and culture media were determined using a heterologous RIA as described by Peter et al. (1984) and Lin et al. (1988) in which the antiserum against the $\beta$-subunit of carp LH was used as the antibody and intact carp LH was used as the standard and tracer.

\section{Statistical analysis}

All data were expressed as mean values \pm s.E.M. Statistical differences were estimated by one-way ANOVA followed by Duncan's multiple range test, and a probability level $<0.05$ $(P<0 \cdot 05)$ was used to indicate significance. All statistics were performed using SPSS 13.0 (SPSS, Chicago, IL, USA).

\section{Results}

Cloning and sequence analysis of kiss 1 and kiss 2 cDNAs in goldfish

Using the methods described in the Materials and Methods section and the primers described in Table 1, two kiss1 cDNA sequences were cloned from goldfish. They are named gfkiss1 and gfkiss2 (GenBank accession number: FJ465137 and FJ465138 respectively). As shown in Fig. 1, the cDNA of gfkiss 1 is $559 \mathrm{bp}$ in length, containing an ORF of $363 \mathrm{bp}$ encoding a precursor protein of 120 amino acids (aa) with a predicted signal peptide of 15 aa. The cDNA of gfkiss 2 is $616 \mathrm{bp}$ in length, containing an ORF of $423 \mathrm{bp}$ encoding a precursor protein of 144 aa with a predicted signal peptide of 22 aa.

Sequence comparison among the deduced aa sequences of the vertebrate Kiss1 precursor proteins shows relatively low identity with each other (Fig. 2). However, the mature peptide (Kiss1-10), the putative functional motif, and also the C-terminal cleavage site (GKR or GRR), are well-conserved across vertebrates. The gfKiss $1-10$ is the same as that of medaka and zebrafish, and differs by only one and two aa with the mouse and human Kiss-10 respectively. Kiss $2-10$ of goldfish, medaka, and zebrafish are identical as well, and differ only by one aa with that of Xenopus, Takifugu, Tetraodon, and lizard. However, the gfKiss1-10 (YNLNSFGLRY) and gfKiss2-10 (FNYNPFGLRF) differ significantly by four aa with each other. Phylogenetic analysis shows that the Kiss1 sequences are clustered into two separate clades, with Kiss1 in one clade and Kiss 2 in the other (Fig. 3A).

Cloning and sequence analysis of GPR 54 cDNAs in goldfish

Two full-length GPR54 cDNAs were cloned from goldfish (named gfGPR54a and gfGPR54b; GenBank accession number: FJ465139 and FJ465140). As shown in Fig. 4, both goldfish GPR54 cDNAs consist of an ORF of $1101 \mathrm{bp}$ encoding a protein of 366 aa in length, with an extracellular $\mathrm{N}$-terminus, a seven transmembrane domain

A

AAAA 4

ATGAAGCTACTTACCATCATCTTGATGTTGTCAGTGGCAAATGGTGATCCATACCCTTCAGGCCATTTTCAATATTATTTAGAAGATGAA 94

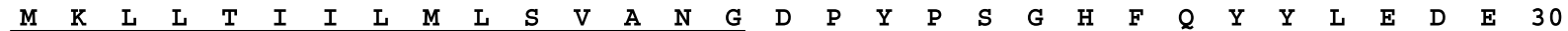
ACTСCTAAAGAATCACTCCAGGTTCTCAGGGGAACTGATACTCGTCCCATGGCTGGATCTCCATCTCCCAAGCTCTCAGTGCACTTCTCC 184 $\begin{array}{lllllllllllllllllllllllllllllllllll}T & P & K & E & S & L & Q & V & L & R & G & T & D & T & R & P & M & A & G & S & P & S & P & K & L & S & V & H & F & S & 60\end{array}$ ATGAGTGCAGATCCTCAGCGAAACACACGGTGGTGGGCTCCTGTAAGACCTTACACAAAAAGGAAGCAGAATGTTGCATACTACAATCTC 274

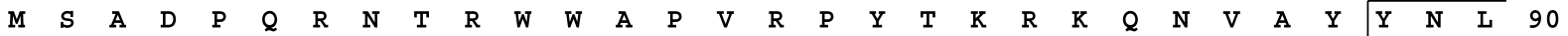
AATTCCTTCGGCCTCCGCTATGGAAAGAGAGAGCAGAACATGCTTGCTGAGTTTAAACAGAAGATACCTATGAAGTGAGGACCACTGGGC 364

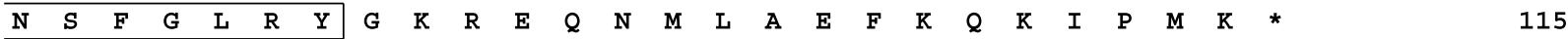
CATGCTAAATCTTGTGTATTGTCGTTGAGGTTTTATATTAATTAGAAATGATTTGTAGATTGATTTCTAGACAAAACATTAGTGCAATA 454 GTTCACAGACTTTAGTAACTGTGAGGACACGTTTTGCTAGTAATAAATACAAACGTTTTGTCAAACAATCTGAATAAAAGGACTTTATTA 544 TAAAAAAAAAAAAAA

\section{B}

TTTGTTCACTGAAGAGAGAAAGGCTCAGCTGTGCTCCATAAGCTTTCCAATTCAGCAGC 59 ATGAAAATCAAGGCACTGATTCTCTTCATGTCTGCAATGATCTGTCAGTCCACAGCTTTGAGAGCCTCATTCACTGACATGGATATATCT 149

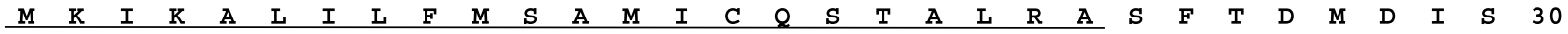
GATTCTGAGCCCGTTCCAGACTCCAAGCAGCACTATCTCTCAGTGGAGCGGAGGCAGTTTGACGAGCCCAGTTCTTCAGACGACGCAAGC 239

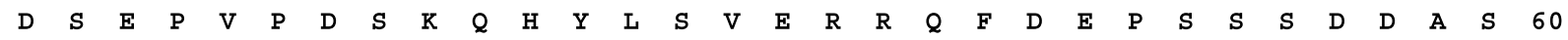
CTTTGTTTTTTCTTCCAAGAAAAAGACGAATCGACACATATTTCCTGCCAACATCGATTACCACGCGGTAAATTCAACTACAACCCGTTT 329

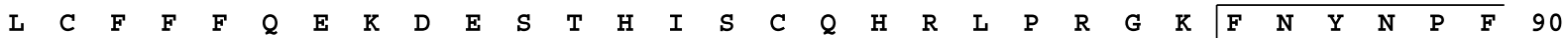
GGGCTGCGCTTTGGGAAGCGAAATGAAGCGCCAACTGACAGACCCAAACACAAGCACCTGCTGCCAATGATGATTTACCTGAGAAAACAG 419 \begin{tabular}{lllllllllllllllllllllllllllllllllll}
\hline$G$ & $L$ & $R$ & $F$ & $G$ & $K$ & $R$ & $N$ & $E$ & $A$ & $P$ & $T$ & $D$ & $R$ & $P$ & $K$ & $H$ & $K$ & $H$ & $L$ & $L$ & $P$ & $M$ & $M$ & $I$ & $Y$ & $L$ & $R$ & $K$ & $Q$ & 120
\end{tabular} TCAGAAACTACTTGAAAATCACATTTCTGTCAGTCTTCATCAGAATGGAAAACTGTGGGTAATTATTTCAGGCACGCCCTGCCTGTTATT 509 $S \quad E \quad T \quad T$ * АTGCTTTTTTTTTTATTTCCCAGTCATGGAATTTTATGGCGCGCTTGTTTCAGTCCGTAATTGTATTTGTGCAATAAACGTTTTATTTTG 599 TTTGAAAAAAAAAAAAA

Figure 1 The nucleotide sequences and the deduced amino acid sequences of goldfish Kiss1 (panel A) and Kiss2 (panel B). The putative signal peptides are underlined. The mature peptides (kisspeptin-10) are boxed. 


Human Kiss1
Pig Kiss1
Mouse Kiss1
Goldfish Kiss1
Zebrafish Kiss1
Goldfish Kiss2
Zebrafish Kiss2
Lizard Kiss2
Xenopus Kiss1
Takifugu Kiss1
Tetraodon Kiss1
Medaka Kiss2
Xenopus Kiss1
Sea lamprey Kiss2
Mekada Kiss1
Sea lamprey Kiss1
Human Kiss1
Pig Kiss1
Mouse Kiss1
Goldfish Kiss1
Zebrafish Kiss1
Goldfish Kiss2
Zebrafish Kiss2
Lizard Kiss1
Xenopus Kiss1
Takifugu Kiss1
Tetraodon Kiss1
Medaka Kiss2
Xenopus Kiss1
Sea lamprey Kiss2
Mekada Kiss1
Sea lamprey Kiss1

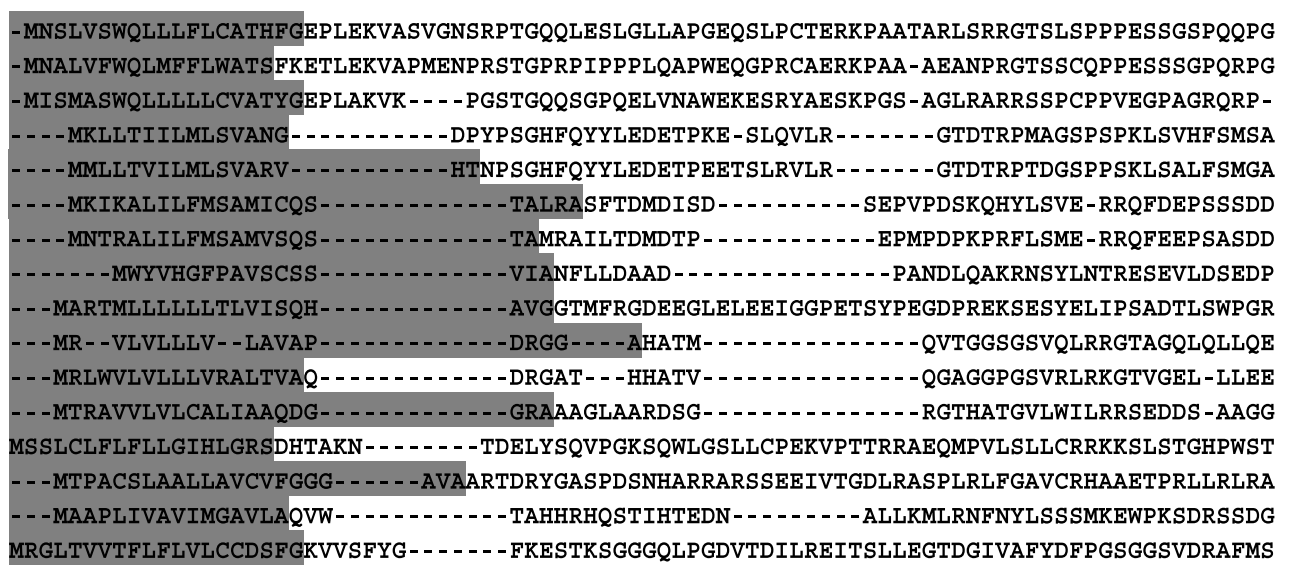

LSAPHSRQI - PAPQGAVLVQREKDLPNYNWNSFGLRFGKR - - EAAP - GNHGRSAGRG - - - - - - - - - - - - - - - - - - - LCTPRSRLI - PAPRGAVLVQREKDLSAYYNWNSFGLRYGKR - - QAAPPGSRNQGAGRD - - - - - - - - - - - - - - - LCASRSRLI - PAPRGAVLVQREKDLSTYYNWNSFGLRYGRR - - - QAAR - - - - - - AARG - - - - - - - -

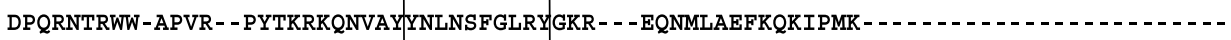
GPQKNTWWW - SPES - - PYTKRRQNVAYYYLLNSFGLRYGGKR - - EQDMLTRLKQKSPVK - - - - - - - - - - - - - - - - ASLCFFFQE -KDESTHISCQHRLPRGKFNYNPFGLRF GKR - - - NEAPT - - -DRPKHKHLLPMMIYLRKQSETT - - - - - - - - ASLCF FIQE-KDETSQISCKHRLARSKFNYNPFGLRF GKR - - NEATTSDSDRLKHKHLLPMMLYLRKQLETS - - - - - - - SSLCYFIQE-SETESQISCRLRFTRSKFNFNPFGLRF GKRQGDTLADDGKLGSQGSRKILQALLKPRLDQTHSQCGENWGDTC SNICYFIRE - GRLESQLSCHLRFTRSKFNFNPFGLRF GKRARGDANGEG - LAPLVPRRLLPFLLK - - - LKDKRCSESVGESC SNPCLTFRD -NED - - QLLCN - - -RSKFNLNPFGLRFGGKR- - - FIYRRAMKQARTHTRSPVSQEVPT- - - - - - - - - - SNPCVALRD -NQD - - QLLCN - - - RSRFNLNPFGLRFGGRR - - - - LVYRRAMKLARTRALPPVSQEVPT - - - - - - - - - - - AGLCSSLRE-DDE - - QLLCAD- - RRSKFNYNPFGLRFGKR - - - APPPRGAHRARAMKLPLMSLFQE- - - - - - - - - DSLLPSRSISAPE-GEFLVQREKDLSTYYNWNSFGLRYGGKR- - - - - GSGSENSKTKVW- - - - - - - LRGGHDLDAGLTDGEALPRSAEQDVTEFNYNPFGLRF GRRSGAQSSTAATRSRAEAACAPGKRGCRLVISKFKLRF - - - - - GTPMVGCWM-VKALHPVAIKKRQDLSSYNLNSFGLRYGK - -

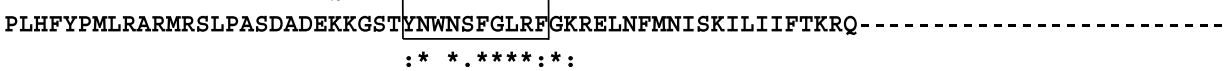

Figure 2 Comparison of amino acid sequences of kisspeptin precursors from different species. The signal peptides are shaded in grey and the mature peptides are boxed. Sequences were aligned by the ClustalW program. Identical sequences are indicated by asterisks. Gaps (indicated by hyphens) are introduced in some sequences to maximize alignment.

and a cytoplasmic C-terminus. The two gfGPR54s share only $55 \cdot 6 \%$ identity in aa sequence with each other. In the phylogenetic analysis (Fig. 3B), it can be seen that gfGPR 54a and gfGPR 54b are clustered into two clearly separate groups.

Tissue distribution of two kiss 1 s and two gpr54s in goldfish

Using gene-specific primers (Table 1) designed from the cloned sequences, RT-PCR analysis was performed to examine the tissue distribution patterns of the two gfkiss 1 and gfgpr 54 genes. As shown in Fig. 5, gfkiss 1 and gfkiss 2 exhibit rather different expression patterns in the central and peripheral tissues. The gfkiss 1 is highly expressed in optic tectum thalamus, intestine, kidney, and testis, with slightly lower levels in hypothalamus and liver. The gfkiss 2 is observed in almost all tissues examined except the cerebellum, with significant expression in the hypothalamus, telencephalon, optic tectum thalamus, adipose tissue, kidney, heart, and gonads.
In the brain regions, high expression of both gfgpr $54 a$ and gfgpr $54 b$ could be detected. In peripheral tissues, gfgpr $54 a$ is expressed exclusively in the gonads and adipose tissue, whereas gfgpr $54 b$ is expressed in all peripheral tissues examined.

Goldfish kisspeptins functionally interact with goldfish GPR 54s expressed on cultured enkaryotic cells

To further characterize the ligand-receptor interactions of the two kisspeptins and the two GPR54s cloned from goldfish, CRE, and SRE reporter gene assays were performed. Cells transfected with the empty vector exhibited no response to the kisspeptins treatment (data no shown). For the CRE promoter, gfKiss1-10 could trigger similar potencies via activating both receptors. For the CRE promoter activity induced by gfKiss $2-10$, no significant post-receptor signaling could be detected in cells transfected with gfGPR 54a but a dose-dependent increase was clearly observed in the gfGPR 54b-expressing cells (Fig. 6A and B). 
For the SRE promoter, gfKiss1-10 could trigger the postreceptor signaling pathway in a clearly dose-dependent manner in cells expressing gfGPR 54a but possesses no significant effect at all on cells expressing gfGPR 54b. On the other hand, gfKiss2-10 exhibits low potency in activating the SRE promoter in cells transfected with gfGPR 54a, but causes a marked increase in the SRE-driven promoter activity in cells expressing gfGPR54b (Fig. 6C and D).

A

GAAAAACTGCCTCAGTGACTAGCATGAATTTTATGAAAAAACACCAGATTCTAAAGGCGTATTCTTTAAATTAATTG 77

GATTGGTGGGCATGGGGACTTTGTCACTGCCAGAAAGAAGAAACTTGACTTTTTTCATCCTGTTTCAAGGTCTCTGCCAAGTCTAAAAAT 167 ATGTTTCCAAGTGAAGATTGGAACTCAAGTGAGCTGCTTAACAGCTCCATTGGAAACTCCTCTATGGAGGACACGGAGGACGAGGAGCAC 257 $\begin{array}{llllllllllllllllllllllllllllllllll}M & F & P & S & E & D & W & N & S & S & E & L & L & N & S & S & I & G & N & S & S & M & E & D & T & E & D & E & E & H & 30\end{array}$ CССTTCCTGACGGATGCTTGGCTGGTGCCCСTTTTCTTCTCCСTCATCATGCTAGTGGGGCTTATCGGAAACTCACTGGTGATCTATGTC 347 $\begin{array}{llllllllllllllllllllllllllllllllll}\mathbf{P} & \mathbf{F} & \text { L } & \text { T } & \text { D } & \text { A } & \text { W } & \text { L } & \text { V } & \text { P } & \text { L } & \text { F } & \text { F } & \text { S } & \text { L } & \text { I } & \text { M } & \text { L } & \text { V } & \text { G } & \text { L } & \text { I } & \text { G } & \text { N } & \text { S } & \text { L } & \text { V } & \text { I } & \text { Y } & \text { V } & 60\end{array}$ ATCTCCAAGCACAGACAGATGAGGACCGCCACTAACTTTTACATTGCCAACTTGGCTGCCACTGACATCATTTTCCTGCTGTGCTGCGTG 437 $\begin{array}{lllllllllllllllllllllllllllllll}\mathbf{I} & \mathbf{S} & \mathbf{K} & \mathbf{H} & \mathbf{R} & \mathbf{Q} & \mathbf{M} & \mathbf{R} & \mathbf{T} & \mathbf{A} & \mathbf{T} & \mathbf{N} & \mathbf{F} & \mathbf{Y} & \mathbf{I} & \mathbf{A} & \mathbf{N} & \mathbf{L} & \mathbf{A} & \mathbf{A} & \mathbf{T} & \mathbf{D} & \mathbf{I} & \mathbf{I} & \mathbf{F} & \mathbf{L} & \mathbf{L} & \mathbf{C} & \mathbf{C} & \mathbf{V} & 90\end{array}$ CCGTTCACTGCTACCCTCTACCCTCTGCCTGGCTGGATATTTGGGGACTTCATGTGCAAATTTGTTGCTTTTCTCCAACAGGTGACCGTA 527

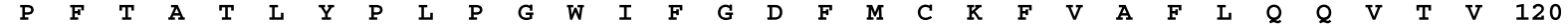
CAGGCGACGTGCATCACTCTTACGGCAATGAGTGGAGACCGTTGCTATGTGACTGTGTATCCTCTGAAATCCCTGCACCACCGAACCCCT 617

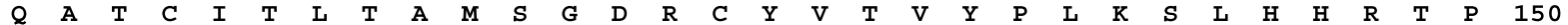
CGTGTCGCAATGATTGTTAGCATCTGTATCTGGATCGGTTCTTCATCCTTTCCATACCAATCTTCCTGTACCAGAGGCTTGAGGATGGC 707

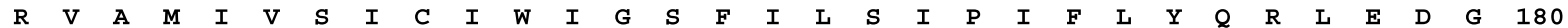
TTTTGGTATGGACCAAGAAAATACTGCATGGAGAGGTTTCCATCAAAGACCCACGAGAAAGCTTTCATCCTCTATCAGTTCATAGCCGTA 797 $\begin{array}{llllllllllllllllllllllllllllllllll}F & W & Y & G & P & R & K & Y & C & M & E & R & F & P & S & K & T & H & E & K & A & F & I & L & Y & Q & F & I & A & V & 210\end{array}$ TATCTACTGCСTGTCATTACCATCTCCTTCTGTTATTCCTTCATGCTGAAGAGAGTGGGACAAGCCTCTGTGGAACCAGTGGATAACAAC 887

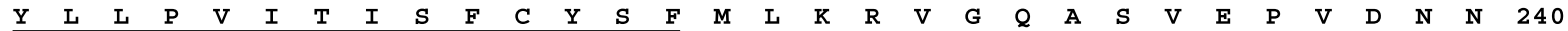
CATCAGGTCCACCTGCTCTCAGAGAGAACTATCTCCATTAGGAGTAAGATTTCCAAAATGGTAGTGGTCATTGTTGTTCTCTTCACCATC 977 $\begin{array}{llllllllllllllllllllllllllllllllll}\text { H } & Q & \text { V } & \text { H } & \text { L } & \text { L } & \text { S } & \text { E } & \text { R } & \text { T } & \text { I } & S & \text { S } & \text { I } & \text { R } & \text { S } & \text { K } & \text { I } & S & \text { K } & \text { M } & \text { V } & \text { V } & \text { V } & \text { I } & \text { V } & \text { V } & \text { L } & F & T & I & 270\end{array}$ TGCTGGGGTCCCATTCAGATCTTTGTCCTGTTCCAGTCTTTCTATCCCAGCTTCAAAGCCAACTACACAACATATAAGATCAAGACATGG 1067 $\begin{array}{llllllllllllllllllllllllllllllll}C & W & G & P & I & Q & I & F & V & L & F & Q & S & F & Y & P & S & F & K & A & N & Y & T & T & Y & K & I & K & T & W & 300\end{array}$ GCCAACTGCATGTCCTATGCCAACTCCTCTATCAACCCTATTGTCTACGGTTTTATGGGCGCCAGCTTCCGCAAGTCCTTCAGGAAGACC 1157

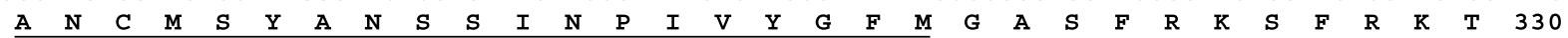
TTTCCCTTCCTCTTCAGACACAAAGTGAGAGACAGCAGTGTCGCCTCCCGCACGGCCAATGCAGAAATAAAGTTCGTAGCAACGGAGGAG 1247

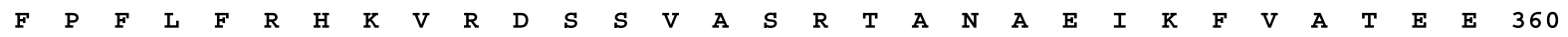
AGCAACACTGAGAGGAAATGAGAGCGGATGACACCTCAACCATGAATCCATGCCAACTGTCTAGTCG $\begin{array}{llllllllll}S & \mathbf{N} & \mathbf{T} & \mathbf{E} & \mathbf{R} & \mathrm{K} & \text { * }\end{array}$

TCTTGTACTATTGGCAGTTTTTTAATTGTTTACAAACCACATGTAAATGACTCTTTCTCTATTTTATTTTACCTAAAAGACCTTTTATAG 113 CAGTGTTTCACACCTAAATGTCATTTAGCTCCTCCCTTTGAGCCGGACTAAATGCAGTCAATGCATGAGTGACCCTCCACTGCAGTGAAG 203 AAGAGTCATGGACCGCTCCGAAACACTCACTGCCCCTTAGGATTGAACGAGGTTTCTGAAAGAGGTTATTGCTAGACCCATGCAAGGCTA 293 ATGGCAGAAAGCAACAGGACCACTGAGGTTGCAGAACTTATCTTGTGCAATAATGAAGCAAATATTTATGATTGCAATCAATCTGATCCC 383 $\begin{array}{llllllllllllllllllllllllllllllll}\mathbf{M} & \mathbf{A} & \mathbf{E} & \mathbf{S} & \mathbf{N} & \mathbf{R} & \mathbf{T} & \mathbf{T} & \mathbf{E} & \mathbf{V} & \mathbf{A} & \mathbf{E} & \mathbf{L} & \mathbf{I} & \mathbf{L} & \mathbf{C} & \mathbf{N} & \mathbf{N} & \mathbf{E} & \mathbf{A} & \mathbf{N} & \mathbf{I} & \mathbf{Y} & \mathbf{D} & \mathbf{C} & \mathbf{N} & \mathbf{Q} & \mathbf{S} & \mathbf{D} & \mathrm{P} & \mathbf{3 0}\end{array}$ ATGGGATCTCAAAGCCCTGTCCCGCTGACAGACGCCTGGCTAGTGCCAGTGTTTTTCATTCTTATATTGTTTGTAGGCTTGGTGGGTAAC 473 $\begin{array}{lllllllllllllllllllllllllllllllll}M & G & S & Q & S & P & V & P & \text { L } & \text { T } & \text { D } & A & \text { W } & \text { L } & \text { V } & \text { P } & \text { V } & \text { F } & \text { F } & \text { I } & \text { L } & \text { I } & \text { L } & \text { F } & \text { V } & G & \text { L } & \text { V } & G & \text { N } & 60\end{array}$ TCACTGGTCATCTATGTAGTCGTCAAAAACCAACAGATGAAAACTGTTACAAACTTCTACATAGTTAATCTTGCCAGCACCGATATACTT 563 $\begin{array}{lllllllllllllllllllllllllllllllll}S & L & V & I & Y & V & V & V & K & N & Q & Q & M & K & T & V & T & N & F & Y & I & V & N & L & A & S & T & D & I & L & 90\end{array}$ TTCCTGGTTTGCTGTTTCCTTTCACTGCCACTTTATACACTCTTCCTAGCTGGATATTTGGGGACTTCATGTGTCGCCTGATCAATTAC 633 $\begin{array}{lllllllllllllllllllllllllllllllllllllll}F & L & V & C & C & V & P & F & T & A & T & L & Y & T & L & P & S & \text { W } & I & F & G & D & F & M & C & R & L & I & N & Y & 120\end{array}$ CTGCAACAGGTAACTGCACAAGCGACCTGCATCACTTTGTCTGCAATGAGTGTTGATCGTTTTTACGTGACGGTCTACCCTCTCCAGTCC 723 $\begin{array}{lllllllllllllllllllllllllllllllllll}\mathrm{L} & \boldsymbol{Q} & \boldsymbol{Q} & \mathrm{V} & \mathrm{T} & \mathrm{A} & \boldsymbol{Q} & \mathrm{A} & \mathrm{T} & \mathrm{C} & \mathrm{I} & \mathrm{T} & \mathrm{L} & \mathrm{S} & \mathrm{A} & \mathrm{M} & \mathrm{S} & \mathrm{V} & \mathrm{D} & \mathrm{R} & \mathrm{F} & \mathrm{Y} & \mathrm{V} & \mathrm{T} & \mathrm{V} & \mathrm{Y} & \mathrm{P} & \mathrm{L} & \boldsymbol{Q} & \mathrm{S} & 150\end{array}$ CTCCGTCATCGAACACCACAGATGGCTCTGTCTGTATGCACCACCATATGGATATGTTCTTTGCTGCTTTCAGTGCCGATAGCGTTGTAT 813 $\begin{array}{llllllllllllllllllllllllllllllllll}L & R & H & R & T & P & Q & M & A & L & S & V & C & T & T & I & W & I & C & S & L & L & L & S & V & P & I & A & L & Y & 180\end{array}$ CAGCACACAGAGTCTTCGTTCTGGTTCGGTCCACAGACGTACTGCACCGAGGCCTTTCCATCTCTCATTCATAAGAGGGCTTACATTCTT 903

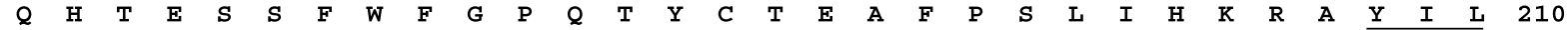
TACTCCTTCTTGGCTGTTTACCTTCTGCCTCTGATCACCATCTGCATGTGTTACACCTTCATGCTGAAGCGCATGGCTCAAGCCACGGTC 993 $\begin{array}{llllllllllllllllllllllllllllllllll}Y & S & F & L & A & V & Y & L & L & P & L & I & T & I & C & M & C & Y & T & F & M & L & K & R & M & A & Q & A & T & V & 240\end{array}$ GGGCCTGCAAATGGCTGTAACCAGCTGCAGACGCCAGCAGAACGTGTTGAAGCAGTGCGGACCAGAGTCACCAGGATGGTGGTTGTAATG 1083

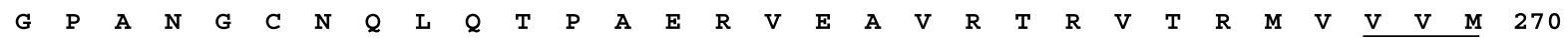
GTGCTGCTGTTTCTGCTCTGCTGGGGTCCAGTCCAGATACTGATTCTCTTACAAGCATTCTGTTCTGAAGACGTGAGTCACAGCTATACA 1173

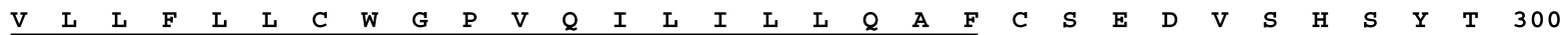
CTCTACAAACTGAAGATCTGGGCTCACTGCATGTCCTACTCCAATTCCTCCATAAACCCCGTCATCTACGCCTTCATGGGAGCCAACTTC 1263

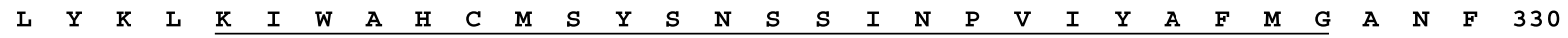
AGAAAGGCCTTCAGAAGTGTGTTCCCTTTGATCTTCAAAAGGGGCGCAAGAACAGCCCAGCCTCTCCCCACCTATAACAGAGAGATGAAC 1353 $\begin{array}{llllllllllllllllllllllllllllllllll}R & K & A & F & R & S & V & F & P & L & I & F & K & R & G & A & R & T & A & Q & P & L & P & T & Y & N & R & E & M & N & 360\end{array}$ TTTCTTTCATCCGGACCCTAGGCGTTTTGGAAAGGCTTTGCGTAAATATTAAATGCAACTAGCTGAACATTAATGTGTTTTTTGTCCCAT 1443 $F \quad L \quad S \quad S \quad G \quad P \quad$ *

TTAAGAAGGACTTAACTGTATCTTTATATGTAATTTCAATAAAAATGTATACGTCTATGAAAAAAAAAAAAAAAAAAA 


\section{Actions of goldfish kisspeptins on LH release}

The in vitro action of the two goldfish kisspeptins on $\mathrm{LH}$ secretion were examined in primary culture of pituitary cells prepared from mature female goldfish. As shown in Fig. 7, neither gfKiss $1-10$ nor gfKiss $2-10$ could significantly stimulate $\mathrm{LH}$ release at any dose after 0.5 or $3 \mathrm{~h}$ of incubation with the peptides, while the positive control LHRHa significantly increased $\mathrm{LH}$ release at $3 \mathrm{~h}$ of incubation.

The in vivo action of the two goldfish kisspeptins on $\mathrm{LH}$ release was also investigated. As shown in Fig. 8, peripheral administration of gfKiss1-10 significantly increased serum LH levels in a dose-dependent manner. At $2 \mathrm{~h}$ after the second injection, all tested doses of gfKiss1-10 significantly increased serum LH levels in the sexually mature female goldfish (Fig. 8A). At $6 \mathrm{~h}$ post-injection, the stimulatory effect was persistent in fish injected with high doses $(0 \cdot 1$ and $1.0 \mu \mathrm{g} / \mathrm{g}$ body weight) of gfKiss1-10. On the other hand, there was no obvious effect of gfKiss $2-10$ on serum LH levels at all doses of the peptide used and at all sampling times (Fig. 8B). The positive control of LHRHa treatment elicited a significant increase in serum LH levels at all time points tested.

\section{Discussion}

In the present study, two kiss1 and two GPR54 sequences were cloned and functionally evaluated in goldfish. Based on synteny analysis, it is proposed that the two kiss 1 genes in fish originated from the same ancestor gene (Felip et al. 2008). Interestingly, deletion of either the kiss 1 or gpr 54 gene in mouse or mutation of the gpr54 gene in human resulted in uncompensated impairment of the reproductive axis (Funes et al. 2003, Seminara et al. 2003, d' Anglemont de Tassigny et al. 2007, Lapatto et al. 2007), indicating that there is no functional redundancy in the kisspeptin/GPR54 system in mammals. A genome-wide scan revealed that only kiss 2 and one type of gpr54 are present in the Takifugu rubripes (Fugu), Tetraodon nigroviridis (pufferfish), and Anolis carolinensis (green anole lizard) genomes, and it seems that chicken has lost both kiss 1s and gpr54s. These observations might be interpreted as the co-evolution of ligand/receptor pairs (Moyle et al. 1994). The loss of either the ligand or the receptor would lead to functional redundancy of its partner, thus both the ligand and the receptor would be lost at last.

Although the two goldfish kisspeptins possess low similarity in primary structure, they still share some features in common such as the relatively well-conserved functional mature peptide regions (Kiss1-10) and C-terminal amide motif. Phylogenetic analysis revealed that gfKiss1 and gfKiss 2 are clustered into two separate branches. Both gfGPR54s contain the NPxxY in the TMH7 and the DRY motif, suggesting that they belong to the rhodposin-like GPCR family (Schwartz et al. 2006). Two goldfish GPR54s share high aa sequence identities in the transmembrane regions, but showed rather low similarities in the extracellular $\mathrm{N}$-terminus and the C-terminal tail.

The expression of the goldfish kiss1s and gpr54s were observed in the neuronal and reproductive related tissues, including the brain, pituitary, and gonads. Nevertheless, the two gfkiss 1 showed rather different expression patterns in the reproduction related tissues, suggesting that the two peptides might play different roles in the fish reproductive system. On the other hand, both gfgpr $54 a$ and $g f g p r 54 b$ are widely expressed in the brain regions, indicating the potential involvement of goldfish kisspeptins in neural functions. In addition, the low expression level of gfkiss $1 \mathrm{~s}$ and gfgpr $54 \mathrm{~s}$ in the pituitary is consistent with the lack of in vitro actions of the peptides on the pituitary cells. Moreover, the goldfish kiss1s and gpr54s mRNA transcripts were also detected in other peripheral tissues, but their physiological significance remains unclear.

Several studies have demonstrated the functional region of kisspeptin, Kiss1-10, transduces its activity via the protein kinase C and protein kinase A pathways (Stafford et al. 2002, Biran et al. 2008, Moon et al. 2009). In the present study, we have examined the ligand specificity of the two goldfish kisspeptins on the two goldfish GPR 54s functionally expressed on cultured eukaryotic cells. It is interesting to note that there are distinct differences in the ligand selectivity exhibited by the two gfGPR 54s. The gfGPR 54a shows high potency to gfKiss $1-10$ activation compared with the gfGPR 54b at high dose, while the gfGPR 54b exhibits higher preference for gfKiss2-10. Distinct differences in the postreceptor signaling events evoked by the ligand-receptor interactions can be observed. It appears that gfKiss1-10

Figure 3 (A) Phylogenetic analysis of kisspeptin precursors in vertebrates. The phylogenetic tree was constructed by MEGA 3.1 using the neighbor-joining method with 1000 bootstrap replicates. The number shown at each branch indicates the bootstrap value (\%). GenBank accession numbers for the sequence are: human Kiss1 (NP_002247); pig Kiss1 (ACH68409.1); mouse Kiss1 (AAl17047); zebrafish Kiss1 (ABV03802), Xenopus Kiss2 (BX850386), zebrafish Kiss2 (AB439561), medaka Kiss2 (AB439562). Sequences predicted from Ensemble: sea lamprey Kiss2 (Contig Contig37453.1 at location 1700-6241); Xenopus Kiss1 (on scaffold_608 at location 39 460-69 716); lizard Kiss2 (on scaffold_15 at location 4601 534-4 601 935); sea lamprey Kiss1, Takifugu, and Tetraodon Kiss2 sequences were previously predicted by van Aerle et al. (2008). (B) Phylogenetic analysis of GPR54 sequences in vertebrates. Phylogenetic tree was performed using MEGA 3.1 by performing using the neighbor-joining method with 1000 bootstrap replicates. The number shown at each branch indicates the bootstrap value (\%). GenBank accession numbers for the sequences are: human GPR54 (AAK83235); rhesus monkey GPR54 (AAV70982); pig GPR54 (ABE73452); dog GPR54 (XP_855198); platypus duckbill GPR54 (XP_001515272); mouse GPR54 (AAK83236); rat GPR54 (AAD19664); grey short-tailed opossum GPR54 (XP_001374752); bull frog GPR54 (ACD44939); tilapia GPR54 (BAD34454); zebrafish GPR54a (ABV44612); zebrafish GPR54b (ABV44613); cobia GPR54 (ABG82165); Atlantic croaker GPR54 (ABC75101); grey mullet GPR54 (ABG76790); senegalese sole (ABW96362). GPR54 predicted by Ensemble: Takifugu GPR54 (ENSTRUG00000013755); medaka GPR54a (ENSORLG00000017731); medaka GPR54b (ENSORLG00000 001694); lizard GPR54 (on scaffold_10 at location 6382 042-6 393 152). 

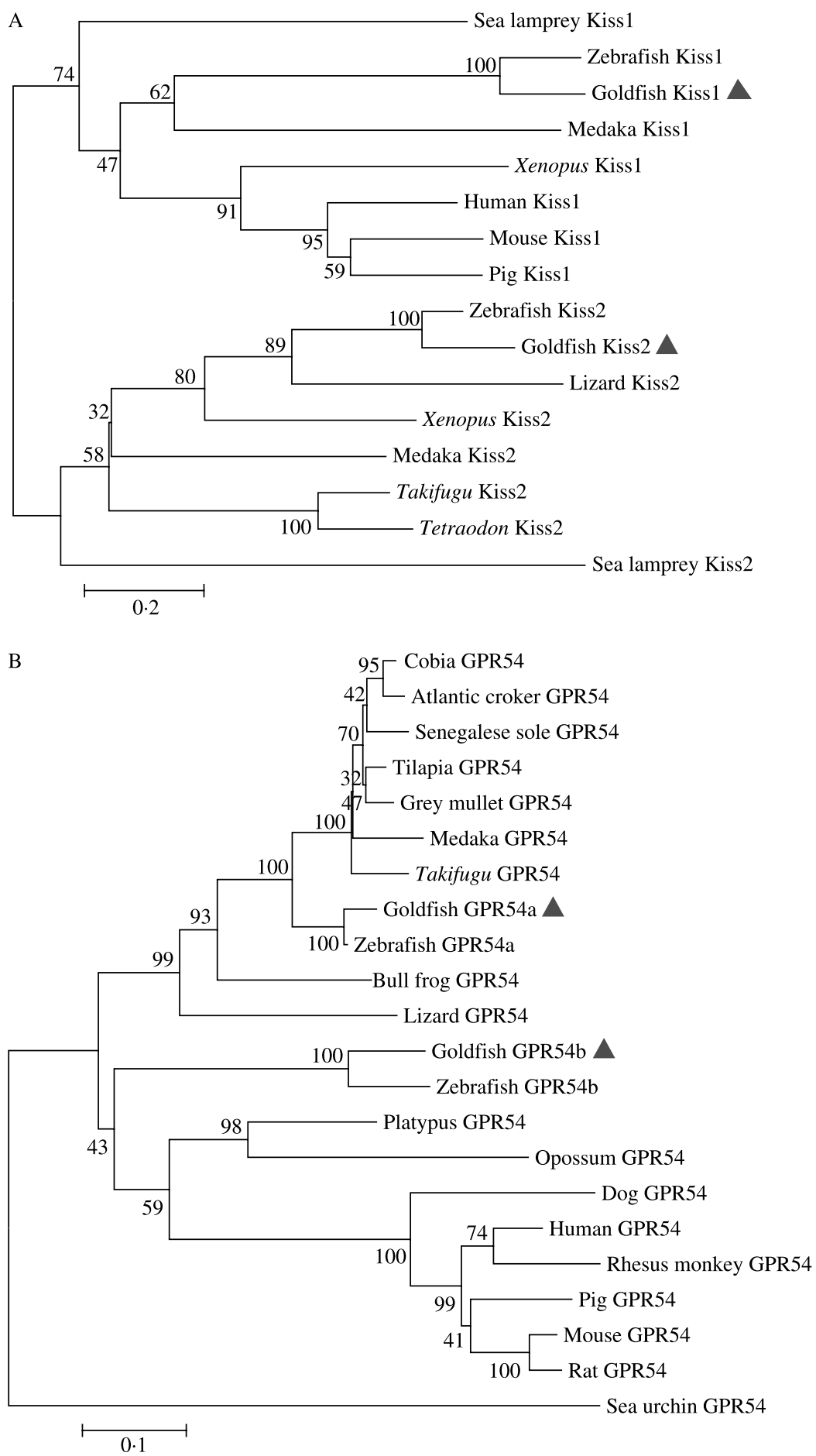

Figure 4 The nucleotide sequences and the deduced amino acid sequences of goldfish GPR54a (A) and GPR54b (B). The transmembrane regions are underlined.

cannot differentiate the two receptors by CRE signaling, whereas the gfKiss $2-10$ can activate CRE signaling of the gfGPR 54b only, but not the gfGPR 54a. On the other hand, a completely different picture is observed for the SRE signaling. The gfKiss $1-10$ can only activate the SRE signaling pathway of gfGPR 54a but not gfGPR 54b, while the preference for the two receptors is reversed for gfKiss $2-10$. The multiplicity of the ligands and the cognate receptors of 


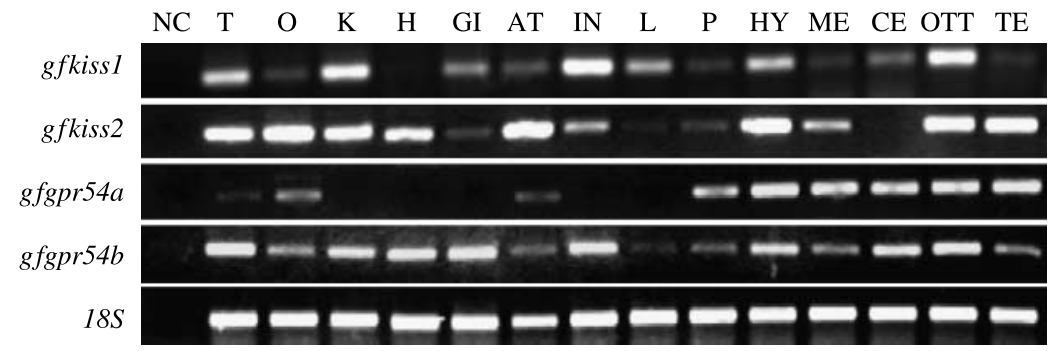

Figure 5 RT-PCR analysis of tissue expression patterns of kiss1, kiss2, gpr54a, gpr54b in goldfish. Amplification of $18 S$ was used as the house-keeping gene control. TE, telencephalon; OTT, optic tectum thalamus; CE, cerebellum; ME, medulla; HY, hypothalamus; P, pituitary; L, liver; IN, intestine; AT, adipose tissue; GI, gill; $\mathrm{H}$, heart; $\mathrm{K}$, kidney; $\mathrm{O}$, ovary; $\mathrm{T}$, testis; $\mathrm{NC}$, negative control.

the kisspeptin/GPR54 system in goldfish do appear to provide additional levels of subtleties in mediating the actions of these peptides through the receptors.

In mammals, kisspeptin plays a central role in controlling reproductive activities by stimulating gonadotropin release which is mediated by increasing hypothalamic GnRH release (Kauffman et al. 2007, Popa et al. 2008). However, it is not known whether kisspeptin in fish serves the same role as their mammalian counterparts on the reproductive axis. In the present study, in vivo administration of synthetic gfKiss $1-10$ potently stimulated LH release in mature female goldfish, indicating that the stimulatory action of kisspeptin on $\mathrm{LH}$ release is conserved from mammals to fish. On the other hand, there is no stimulatory effect on LH secretion in cultured pituitary cells from mature female goldfish, suggesting that Kiss1-10 does not act at the pituitary level to exert its physiological effect. In tilapia, gpr 54 was expressed in GnRH neurons (Parhar et al. 2004), affording the important proof for the direct regulation of $\mathrm{GnRH}$ secretion by fish kisspeptin. In our studies, it was observed that both the goldfish kiss1s and gpr54s are abundantly expressed in the central nervous system, especially in the hypothalamus. Taken together, these results suggest that the increase of serum $\mathrm{LH}$ levels observed in vivo after gfKiss $1-10$ administration is probably caused by increase of $\mathrm{GnRH}$ release in the hypothalamus. The in vivo potencies of the two goldfish kisspeptins are very different with no significant LH-release activities observed for the gfKiss $2-10$. The differences in the in vivo effect of goldfish kisspeptins on $\mathrm{LH}$ release might be caused by their sequence variations in the functional region. The gfKiss1-10 and gfKiss2-10 differ with each other by four aa. Thus, the two kiss 1 genes in goldfish might acquire different functions during the long time of evolution. Despite that Kiss 2-10 might lose its ability to elicit LH release in goldfish, several observations indicated that it might play other important functions, e.g., the preservation of the gene as well as the functional motif of Kiss $2-10$ during the long evolutionary history; the ability of gfKiss $2-10$ to activate the gfGPR54 functionally expressed on cultured eukaryotic cells with a clear preference towards gfGPR 54a; and the existence of only kiss 2 in some species (Felip et al. 2008). During the preparation of this manuscript, Kitahashi et al. (2008) reported that zebrafish Kiss1-10 had no effect on the gene expression of gonadotropins ( $l h b$ and $f s h b$ ), but zebrafish Kiss 2 peptide significantly increased the $l h b$ and $f s h b$ mRNA levels in the pituitary of sexually mature zebrafish after peripheral administration. And more recently, Alicia Felip et al. (2008) reported that Kiss-2 peptide is more potent than Kiss-1 in inducing gonadotropin secretion in sea bass. Taken together,

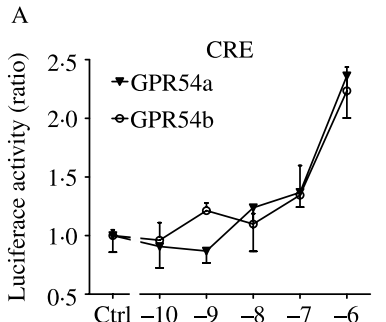

C
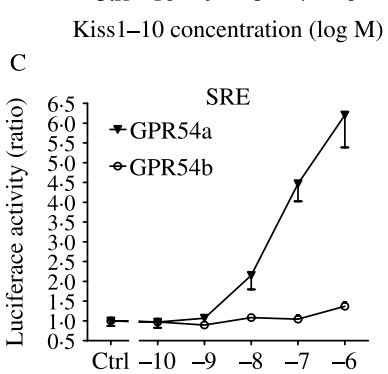

Kiss $1-10$ concentration $(\log \mathrm{M})$

\section{B}

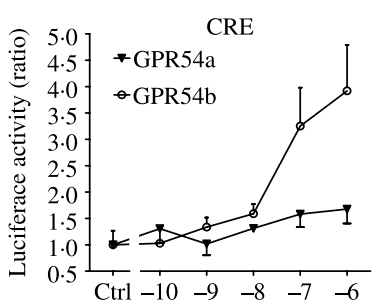

Kiss $2-10$ concentration $(\log M)$

$\mathrm{D}$

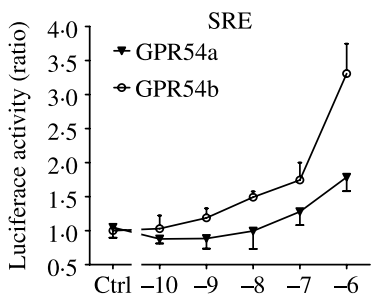

Kiss $2-10$ concentration $(\log \mathrm{M})$
Figure 6 Functional interaction between goldfish kisspeptins and goldfish GPR54s. Induction of CRE-driven luciferase activities in COS-7 cells transfected with GPR54a or GPR54b by Kiss1-10 (A) and Kiss2-10 (B). Induction of SRE-driven luciferase activities in COS-7 cells transfected with GPR54a or GPR54b by Kiss1-10 (C) and Kiss2-10 (D). Results are mean values \pm s.E.M. from three independent experiments each conducted in triplicates, and expressed as the ratio of increase in luciferase activity above the control (in the absence of any stimulating peptide). 


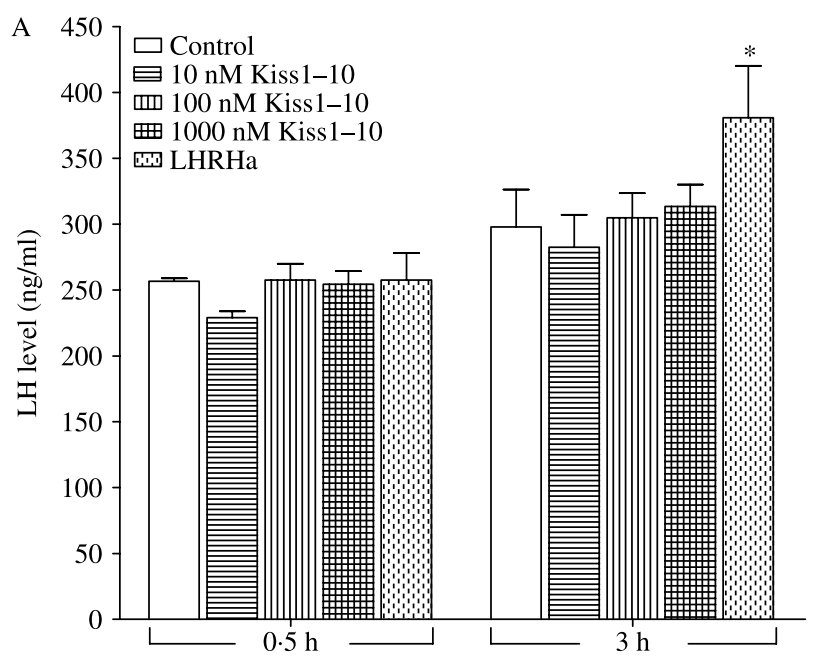

Hours after incubation with peptide

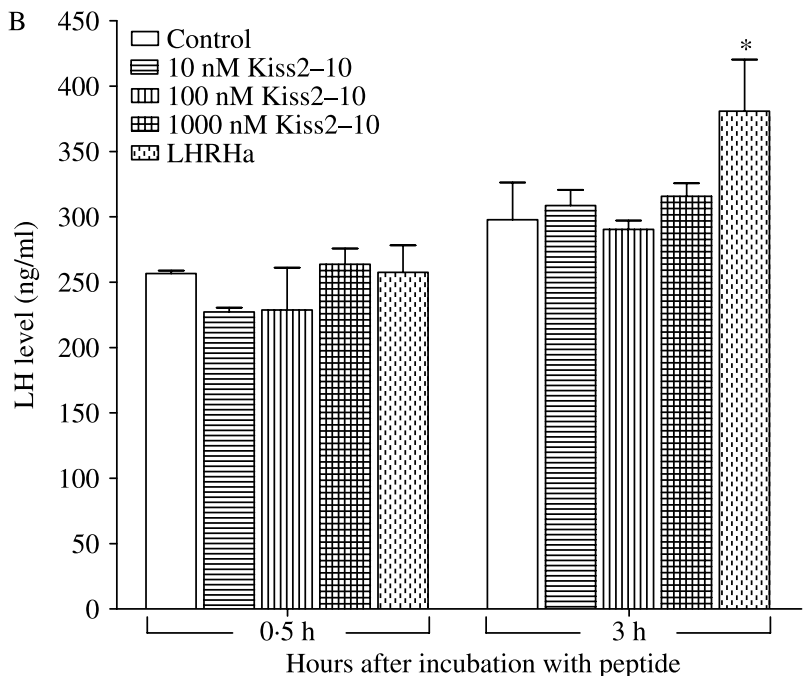

Figure 7 In vitro action of goldfish Kiss1-10 (A) and Kiss2-10 (B) on $\mathrm{LH}$ release in goldfish pituitary cells. Primary culture of goldfish pituitary cells were challenged with different concentrations of the goldfish kisspeptins and $10^{-8} \mathrm{M}$ of LHRHa was used as the positive control. The cell culture media were harvested at 30 and $180 \mathrm{~min}$, and LH levels were determined. Hormone values are expressed as mean values \pm S.E.M. $(n=4) .{ }^{*} P<0 \cdot 05$ versus the corresponding control.

these results suggest that the two kisspeptins in teleost fish have evolved differentially and the relative importance of the two peptides in regulating gonadotropin secretion varies greatly in different species.

In conclusion, we have cloned two kiss1 and two gpr54 cDNA sequences from goldfish, and demonstrated that the two goldfish kisspeptins possess different features in terms of their primary structure, expression profile, receptor subtype preference, and signaling pathway specificity. And for the first time, we have demonstrated that gfKiss1-10 stimulates LH release in vivo in goldfish. These results provide strong evidence for the structural and functional conservation of the kisspeptin/GPR54 system in the regulation of the reproductive axis across vertebrates. The multiplicity of the peptides and the receptors in telesot fish provide the basis for the subtle differences of this system in various fish species. The elucidation of the kisspeptin/GPR54 system in a fish species where the neuroendocrine control of reproduction is well studied paves the way for further evaluating the significance and the detailed mechanisms of how this system controls reproduction.
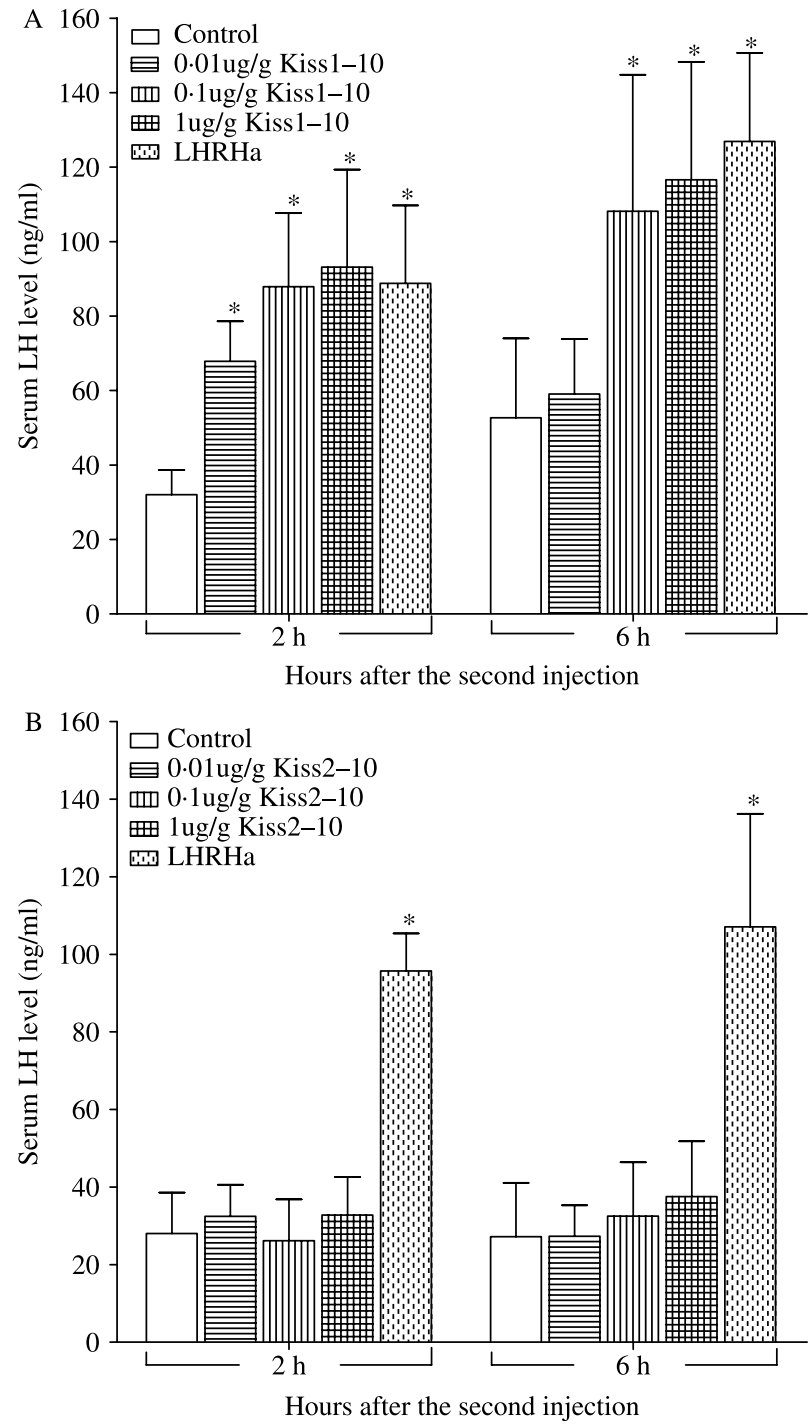

Figure 8 In vivo action of goldfish Kiss1-10 (A) and Kiss2-10 (B) on $\mathrm{LH}$ release in goldfish. Goldfish were injected i.p. with different amounts of goldfish kisspeptins and $10^{-8} \mathrm{ng} / \mathrm{g}$ body weight of LHRHa was used as the positive control. Blood samples were collected and serum LH levels were determined 2 and $6 \mathrm{~h}$ post injection. Hormone values are expressed as mean values \pm S.E.M. $(n=7-9) .{ }^{*} P<0 \cdot 05$ versus the corresponding control. 


\section{Declaration of interest}

The authors declare that there is no conflict of interest that would prejudice the impartiality of this scientific work.

\section{Funding}

This project was supported by the National Science Foundation of China (No. 30700611, U0631007), grants from Zhuhai Science, and Technology project (PC20041141), the Hi-Tech Research and Development Program of China 863 Projects (No. 2006AA10A402) and the National Key Technology Research and Development Program (2006BAD09A14 and 2007BAD29B01). We also thank The Chinese University of Hong Kong and United College for the provision of Direct Grants and financial support.

\section{References}

Van Aerle R, Kille P, Lange A \& Tyler CR 2008 Evidence for the existence of a functional Kiss1/Kiss1 receptor pathway in fish. Peptides 29 57-64.

d' Anglemont de Tassigny X, Fagg LA, Dixon JP, Day K, Leitch HG, Hendrick AG, Zahn D, Franceschini I, Caraty A, Carlton MB et al. 2007 Hypogonadotropic hypogonadism in mice lacking a functional Kiss 1 gene. PNAS 104 10714-10719.

Bendtsen JD, Nielsen H, Heijne GV \& Brunak S 2004 Improved prediction of signal peptides: SignalP 3.0. Journal of Molecular Biology 340 783-795.

Biran J, Ben-Dor S \& Levavi-Sivan B 2008 Molecular identification and functional characterization of the kisspeptin/kisspeptin receptor system in lower vertebrates. Biology of Reproduction 79 776-786.

Felip A, Zanuy S, Pineda R, Pinilla L, Carrillo M, Tena-Sempere M \& Gómez A 2008 Evidence for two distinct KiSS genes in non-placental vertebrates that encode kisspeptins with different gonadotropin-releasing activities in fish and mammals. Molecular and Cellular Endocrinology (doi: 10.1016/j.mce.2008.11.017).

Funes S, Hedrick JA, Vassileva G, Markowitz L, Abbondanzo S, Golovko A, Yang S, Monsma FJ \& Gustafson EL 2003 The KiSS-1 receptor GPR54 is essential for the development of the murine reproductive system. Biochemical and Biophysical Research Communications 312 1357-1363.

Gottsch ML, Cunningham MJ, Smith JT, Popa SM, Acohido BV, Crowley WF, Seminara S, Clifton DK \& Steiner RA 2004 A role for kisspeptins in the regulation of gonadotropin secretion in the mouse. Endocrinology 145 4073-4077.

Gutierrez-Pascual E, Martinez-Fuentes AJ, Pinilla L, Tena-Sempere M, Malagon MM \& Castano JP 2007 Direct pituitary effects of kisspeptin: activation of gonadotrophs and somatotrophs and stimulation of luteinising hormone and growth hormone secretion. Journal of Neuroendocrinology 19 521-530.

Irwig MS, Fraley GS, Smith JT, Acohido BV, Popa SM, Cunningham MJ, Gottsch ML, Clifton DK \& Steiner RA 2005 Kisspeptin activation of gonadotropin releasing hormone neurons and regulation of KiSS-1 mRNA in the male rat. Neuroendocrinology 80 264-272.

Kauffman AS, Clifton DK \& Steiner RA 2007 Emerging ideas about kisspeptin-GPR54 signaling in the neuroendocrine regulation of reproduction. Trends in Neurosciences 10 504-511.

Kitahashi T, Ogawa S \& Pahar IS 2008 Cloning and expression of kiss 2 in the zebrafish and medaka. Endocrinology 150 821-831.

Kotani M, Detheux M, Vandenbogaerde A, Communi D, Vanderwinden JM, Le Poul E, Brezillon S, Tyldesley R, Suarez-Huerta N, Vandeput F et al. 2001 The metastasis suppressor gene KiSS-1 encodes kisspeptins, the natural ligands of the orphan $G$ protein-coupled receptor GPR 54. Journal of Biological Chemistry 276 34631-34636.

Kumar S, Tamura K \& Nei M 2004 MEGA3: integrated software for molecular evolutionary genetics analysis and sequence alignment. Briefings in Bioinformatics 5 150-163.
Lapatto R, Pallais JC, Zhang D, Chan Y, Mahan A, Cerrato F, Le WW, Hoffman GE \& Seminara SB 2007 Kiss 1- / - mice exhibit more variable hypogonadism than Gpr54-/- mice. Endocrinology 148 4927-4936.

Lee JH \& Welch DR 1997 Suppression of metastasis in human breast carcinoma MDA-MB-435 cells after transfection with the metastasis suppressor gene, KiSS-1. Cancer Research 57 2384-2387.

Lee JH, Miele ME, Hicks DJ, Phillips KK, Trent JM, Weissman BE \& Welch DR 1996 KiSS-1, a novel human malignant melanoma metastasis-suppressor gene. Journal of the National Cancer Institute $\mathbf{8 8}$ 1731-1737.

Lin HR, Van DKG, Zhou XJ, Liang JY, Peter RE, Rivier JE \& Vale WW 1988 Effects of [D-Arg6, trp7, Leu8, Pro9NEt]-luteinizing hormonereleasing hormone (sGnRH-A) and [D-Ala6, Pro9NEt]-luteinizing hormone-releasing hormone (LHRH-A), in combination with pimozide or domperidone, on gonadotropin release and ovulation in the Chinese loach and common carp. General and Comparative Endocrinology 69 31-40.

Matsui H, Takatsu Y, Kumano S, Matsumoto H \& Ohtaki T 2004 Peripheral administration of metastin induces marked gonadotropin release and ovulation in the rat. Biochemical and Biophysical Research Communications 320 383-388.

Messager S, Chatzidaki EE, Ma D, Hendrick AG, Zahn D, Dixon J, Thresher RR, Malinge I, Lomet D, Carlton MB et al. 2005 Kisspeptin directly stimulates gonadotropin-releasing hormone release via $\mathrm{G}$ protein-coupled receptor 54. PNAS 102 1761-1766.

Moon JS, Lee YR, Oh DY, Hwang JI, Lee JY, Kim JI, Vaudry H, Kwon HB \& Seong JY 2009 Molecular cloning of the bullfrog kisspeptin receptor Gpr54 with high sensitivity to Xenopus kisspeptin. Peptides 30 171-179.

Moyle WR, Campbell RK, Myers RV, Bernard MP, Han Y \& Wang X 1994 Co-evolution of ligand-receptor pairs. Nature 368 251-255.

Muir AI, Chamberlain L, Elshourbagy NA, Michalovich D, Moore DJ, Calamari A, Szekeres PG, Sarau HM, Chambers JK, Murdock P et al. 2001 AXOR12, a novel human $G$ protein-coupled receptor, activated by the peptide KiSS-1. Journal of Biological Chemistry 276 28969-28975.

Navarro VM, Castellano JM, Fernandez-Fernandez R, Barreiro ML, Roa J, Sanchez-Criado JE, Aguilar E, Dieguez C, Pinilla L \& Tena-Sempere M 2004 Developmental and hormonally regulated messenger ribonucleic acid expression of KiSS-1 and its putative receptor, GPR 54, in rat hypothalamus and potent luteinizing hormone-releasing activity of KiSS-1 peptide. Endocrinology 145 4565-4574.

Ohtaki T, Shintani Y, Honda S, Matsumoto H, Hori A, Kanehashi K, Terao Y, Kumano S, Takatsu Y, Masuda Y et al. 2001 Metastasis suppressor gene KiSS-1 encodes peptide ligand of a G-protein-coupled receptor. Nature $\mathbf{4 1 1}$ 613-617.

Parhar IS, Ogawa S \& Sakuma Y 2004 Laser-captured single digoxigeninlabeled neurons of gonadotropin-releasing hormone types reveal a novel G protein-coupled receptor (Gpr54) during maturation in cichlid fish. Endocrinology 145 3613-3618.

Peter RE, Nahorniak CS, Chang JP \& Crim L 1984 Gonadotropin release from the pars distalis of goldfish, Carassius auratus, transplanted beside the brain or into the brain ventricles. General and Comparative Endocrinology $\mathbf{5 5}$ 337-346.

Plant TM, Ramaswamy S \& Dipietro MJ 2006 Repetitive activation of hypothalamic $\mathrm{G}$ protein-coupled receptor 54 with intravenous pulses of kisspeptin in the juvenile monkey (Macaca mulatta) elicits a sustained train of gonadotropin-releasing hormone discharges. Endocrinology 147 1007-1013.

Popa SM, Clifton DK \& Steiner RA 2008 The role of Kisspeptins and GPR 54 in the neuroendocrine regulation of reproduction. Annual Review of Physiology 70 213-238.

Popesku JT, Martyniuk CJ, Mennigen J, Xiong H, Zhang D, Xia X, Cossins AR \& Trudeau VL 2008 The goldfish (Carassius auratus) as a model for neuroendocrine signaling. Molecular and Cellular Endocrinology 293 43-56.

De Roux N, Genin E, Carel JC, Matsuda F, Chaussain JL \& Milgrom E 2003 Hypogonadotropic hypogonadism due to loss of function of the KiSS1-derived peptide receptor GPR54. PNAS 100 10972-10976.

Schwartz TW, Frimurer TM, Holst B, Rosenkilde MM \& Elling CE 2006 Molecular mechanism of 7TM receptor activation - a global toggle switch model. Annual Review of Pharmacology and Toxicology 46 481-519. 
Seminara SB, Messager S, Chatzidaki EE, Thresher RR, Acierno JS Jr, Shagoury JK, Bo-Abbas Y, Kuohung W, Schwinof KM, Hendrick AG et al. 2003 The GPR 54 gene as a regulator of puberty. New England Journal of Medicine 349 1614-1627.

Shahab M, Mastronardi C, Seminara SB, Crowley WF, Ojeda SR \& Plant TM 2005 Increased hypothalamic GPR54 signaling: a potential mechanism for initiation of puberty in primates. PNAS 102 2129-2134.

Smith JT, Rao A, Pereira A, Caraty A, Millar RP \& Clarke IJ 2008 Kisspeptin is present in ovine hypophysial portal blood but does not increase during the preovulatory luteinizing hormone surge: evidence that gonadotropes are not direct targets of kisspeptin in vivo. Endocrinology 149 1951-1959.

Southey BR, Amare A, Zimmerman TA, Rodriguez-Zas SL \& Sweedler JV 2006 NeuroPred: a tool to predict cleavage sites in neuropeptide precursors and provide the masses of the resulting peptides. Nucleic Acids Research 34 267-272.

Stafford LJ, Xia C, Ma N, Cai Y \& Liu M 2002 Identification and characterization of mouse metastasis-suppressor KiSS1 and its G-proteincoupled receptor. Cancer Research 62 5399-5404.
Suzuki S, Kadokawa H \& Hashizume T 2008 Direct kisspeptin-10 stimulation on luteinizing hormone secretion from bovine and porcine anterior pituitary cells. Animal Reproduction Science 105 404-408.

Thompson JD, Higgins DG \& Gibson TJ 1994 CLUSTAL W: improving the sensitivity of progressive multiple sequence alignment through sequence weighting, position-specific gap penalties and weight matrix choice. Nucleic Acids Research 22 4673-4680.

Thompson EL, Patterson M, Murphy KG, Smith KL, Dhillo WS, Todd JF, Ghatei MA \& Bloom SR 2004 Central and peripheral administration of kisspeptin-10 stimulates the hypothalamic-pituitary-gonadal axis. Journal of Neuroendocrinology 16 850-858.

Received in final form 12 March 2009

Accepted 20 March 2009

Made available online as an Accepted Preprint 20 March 2009 